\title{
Comparison of laparoscopic vs. open surgery for rectal cancer
}

\author{
ZIHAI DING ${ }^{1}$, ZHENG WANG $^{1,2}$, SHIJIE HUANG ${ }^{3}$, SHIZHEN ZHONG ${ }^{1}$ and JIANHUA LIN ${ }^{4}$ \\ ${ }^{1}$ Anatomical Institute of Minimally Invasive Surgery, Southern Medical University, Guangzhou, Guangdong 510515; \\ ${ }^{2}$ Department of General Surgery, Guangzhou Hospital of Integrated Traditional Chinese and Western Medicine, Guangzhou, \\ Guangdong 510800; ${ }^{3}$ Department of Gastrointestinal Surgery, The Fourth Affiliated Hospital of Jinan University, \\ Guangzhou Red Cross Hospital, Guangzhou, Guangdong 510220; ${ }^{4}$ Department of Hepatobiliary Surgery, \\ Nanfang Hospital Affiliated to Southern Medical University, Guangzhou, Guangdong 510515, P.R. China
}

Received June 6, 2016; Accepted October 4, 2016

DOI: $10.3892 / \mathrm{mco} .2016 .1112$

\begin{abstract}
This study was conducted to evaluate the safety of laparoscopic radical resection for rectal cancer. A total of 64 cases of rectal cancer patients undergoing radical surgery between January, 1998 and March, 2010 were collected. The patients were divided into the laparoscopic rectal surgery group (LS group, $\mathrm{n}=31$ ) and the open surgery group (OS group, $\mathrm{n}=33$ ). Operation time, postoperative recovery, complications and tumor-free survival rate were compared between the two groups. The inclusion criteria were as follows: Standard Karnofsky score $>70$ prior to surgery, definitive pathological diagnosis and complete clinical data. The exclusion criteria were concomitant tumors affecting survival. With the Dixon operation, the LS group had a longer operation time compared with the OS group (271.2 \pm 56.2 vs. $216.0 \pm 62.7 \mathrm{~min}$, respectively; $\mathrm{P}=0.036$ ), and an earlier time of oral intake (3.0 \pm 0.9 vs. $4.7 \pm 1.0$ days, respectively; $\mathrm{P}=0.000)$. There were no significant differences between the LS and OS groups in terms of intraoperative blood loss, number of lymph nodes retrieved, duration of postoperative hyperthermia and hospitalization time $(\mathrm{P}>0.05)$. With the Miles operation, there were no obvious differences between the LS and OS groups regarding operation time, intraoperative blood loss, number of lymph nodes retrieved, time of oral intake, duration of postoperative hyperthermia and hospitalization time $(\mathrm{P}>0.05)$. Furthermore, there were no significant differences between the LS and OS
\end{abstract}

Correspondence to: Dr Zheng Wang, Department of General Surgery, Guangzhou Hospital of Integrated Traditional Chinese and Western Medicine, 87 Yingbin Road, Huadu, Guangzhou, Guangdong 510800, P.R. China

E-mail:wzsjw@126.com

Dr Shijie Huang, Department of Gastrointestinal Surgery, The Fourth Affiliated Hospital of Jinan University, Guangzhou Red Cross Hospital, 396 Tongfu Middle Road, Haizhu, Guangzhou, Guangdong 510220, P.R. China

E-mail: gzdthsj@163.com

Key words: rectal cancer, laparoscopic, open surgery, radical resection groups with the Dixon or Miles operation in terms of 3-year tumor-free survival rate $(\mathrm{P}>0.05)$. Thus, laparoscopic surgery appears to be a safe and feasible option for the treatment of rectal cancer.

\section{Introduction}

Rectal cancer is the second and the third most common type of cancer in developed countries and worldwide, respectively, with a male: Female incidence ratio of (2-3):1 (1). Thus, a safe and feasible treatment for rectal cancer is urgently required. In 1900, laparoscopy was first used for right hemicolectomy, which was the origin of laparoscopic surgery for colorectal cancer (2,3). It was then used by Jacobs in 1991 (4), which pioneered the era of laparoscopic rectal cancer surgery. At present, laparoscopic surgery for rectal cancer is developing rapidly in China, and is acknowledged by several doctors and patients. However, it has not yet been widely approved or included in international treatment guidelines. The aim of the present study was to evaluate the curative effect of this type of surgery for rectal cancer in order to promote its wider application worldwide.

\section{Patients and methods}

Patient selection. A total of 64 cases of rectal cancer patients were randomly divided into the laparoscopic surgery group (LS, $n=31)$ and the open surgery group (OS, n=33). A comparison was made between the two groups according to the clinical data. The patient selection criteria were as follows: All the patients consented to participate in this study, they were all pathologically diagnosed preoperatively via colonofiberscopic biopsy, without evidence of distant metastases to the lung, abdominal cavity, liver or pelvic cavity prior to and during the operation. In addition, the patients were suitable candidates for radical cancer resection. Open or laparoscopic surgery was selected according to the wishes of the patients. The inclusion criteria for the study were as follows: All the patients were diagnosed with rectal cancer, the standard Karnofsky score was $>70$ prior to surgery, there was a definitive pathological diagnosis and complete clinical data. The exclusion criteria were patients with concomitant tumors that significantly affected survival. Patients with pT4 and pN2 were not included 
in the study, as such patients were only treated with open surgery in our hospital at that time.

None of the two groups received neoadjuvant chemotherapy. The surgeries were performed according to the total mesorectal excision (TME) principle. The extent of tumor resection of these two groups was determined with the aim to achieve negative circumferential and distal margins. There was no statistically significant difference between the two groups ( $P>0.05)$ regarding age, gender, body mass index, localization and topography of the tumor, pathological stage, type of surgery, status of the circumferential and distal margins, quality of mesorectal excision, $\mathrm{pT}$ and $\mathrm{pN}$ stage of the tumor. The comparison is summarized in Table I. In both groups, a proportion of the patients received anterior resection (Dixon), whereas the remaining patients received abdominoperineal resection (Miles). Thus, as shown in Tables II and III, the comparisons between these two operations were separately performed. Furthermore, patients undergoing the open Dixon procedure received more postoperative adjuvant chemotherapy compared with those undergoing the laparoscopic Dixon procedure $(\mathrm{P}=0.019)$.

Patient records/information were anonymized and de-identified prior to analysis. Our research was performed in accordance with the principles outlined in the Declaration of Helsinki and was approved by the Medical Ethics Committee of the Guangzhou Hospital of Integrated Traditional Chinese and Western Medicine.

Surgical procedures. The surgical operating principles of the LS and OS groups were the same, following strict rules for achieving a tumor-free status. In both groups, patients underwent the Miles or Dixon operation. The Dixon operation was selected if the tumor was located $\leq 5 \mathrm{~cm}$ from the anus, whereas the Miles operation was selected if the tumor was located $\geq 5 \mathrm{~cm}$ from the anus.

Perioperative and postoperative management protocols. On the day prior to the operation, the auxiliary examinations and preparation were completed and there were no obvious surgical contraindications. The blood pressure and blood sugar levels were effectively controlled. The patients were administered a full liquid diet, intravenous nutrition and oral antibiotics and underwent an enema, skin preparation and preoperative fasting for $12 \mathrm{~h}$. On the day of the operation, a nasogastric tube was inserted and intravenous prophylactic antibiotics were administered $30 \mathrm{~min}$ prior to the operation. On the day after the operation, the patients underwent gastrointestinal decompression, indwelling catheterization and electrocardiographic monitoring. The fluid draining from the peritoneal cavity via the drainage tube was carefully observed. After the operation, the patients received routine intravenous antibiotics and intravenous nutrition. Early ambulation was encouraged. The patients were fasted and received gastrointestinal decompression until they passed gas, then were given a full liquid diet for 3 days, a semi-liquid diet for another 3 days and a normal diet thereafter. If the patients had been eating well without any feeling of abdominal discomfort, the peritoneal drainage tube was removed and the intravenous liquid was gradually reduced. The sutures were removed $\sim 1$ week after the operation. Chemotherapy was considered 1 month after the
Table I. Comparison of general clinical data between the LS and OS groups.

\begin{tabular}{|c|c|c|c|}
\hline Parameters & $\begin{array}{l}\text { LS group } \\
\quad(n=31)\end{array}$ & $\begin{array}{l}\text { OS group } \\
(n=33)\end{array}$ & P-value \\
\hline Age, years (mean \pm SD) & $65.6 \pm 10.9$ & $63.0 \pm 1.8$ & 0.448 \\
\hline Gender (male/female) & $18 / 13$ & $19 / 14$ & 0.968 \\
\hline $\mathrm{BMI}, \mathrm{kg} / \mathrm{m}^{2}($ mean $\pm \mathrm{SD})$ & $22.6 \pm 3.3$ & $23.3 \pm 3.0$ & 0.624 \\
\hline $\begin{array}{l}\text { Tumor location } \\
\text { (distance from anus, cm) }\end{array}$ & $7.8 \pm 4.8$ & $8.6 \pm 3.4$ & 0.669 \\
\hline TNM stage & & & 0.999 \\
\hline 0 & 1 & 1 & \\
\hline I & 14 & 15 & \\
\hline II & 10 & 11 & \\
\hline III & 6 & 6 & \\
\hline pT stage & & & 0.921 \\
\hline Tis & 2 & 1 & \\
\hline $\mathrm{T} 1$ & 3 & 4 & \\
\hline $\mathrm{T} 2$ & 10 & 11 & \\
\hline $\mathrm{T} 3$ & 16 & 17 & \\
\hline pN stage & & & 0.911 \\
\hline No & 22 & 23 & \\
\hline $\mathrm{N} 1$ & 9 & 10 & \\
\hline Type of surgery & & & 1.000 \\
\hline Anterior resection & 21 & 22 & \\
\hline AP excision & 10 & 11 & \\
\hline
\end{tabular}

There was no significant difference between the LS and OS groups regarding general clinical data $(\mathrm{P}>0.05)$. LS, laparoscopic surgery; OS, open surgery; BMI, body mass index; SD, standard deviation; TNM, tumor-node-metastasis; AP, abdominoperineal.

operation on the basis of the pathological stage. Chemotherapy in patients undergoing laparoscopic surgery was initiated earlier compared with patients undergoing open surgery due to the shorter recovery time following laparoscopy. The chemotherapeutic regimen was generally FOLFOX or FOLFIRI. Two patients with pathological stage I and 32 patients with pathological stage $\geq$ II disease received adjuvant chemotherapy following surgery. In addition, patients with residual lesions were treated with postoperative radiotherapy.

Observation index and follow-up. Indices such as operation time, intraoperative blood loss, number of lymph nodes retrieved, time to oral intake of food, duration of postoperative hyperthermia and hospitalization time were recorded. The patients were observed for postoperative complications, including pulmonary infection, formation of fistulas and intestinal adhesions.

Clinical physical examination, measurement of carcinoembryonic antigen levels, computed tomography and colonoscopy were used for follow-up. The patients were followed up yearly after the operation. Thorough follow-up protocols were applied to assess local recurrence, pulmonary metastasis and multiple metastases. Survival status was constantly assessed and the 3-year tumor-free survival rate was calculated. 
Table II. Comparison of general clinical data between the LS and OS groups with the Dixon operation.

\begin{tabular}{|c|c|c|c|}
\hline Parameters & $\begin{array}{l}\text { LS group } \\
(\mathrm{n}=20)\end{array}$ & $\begin{array}{l}\text { OS group } \\
(n=21)\end{array}$ & P-value \\
\hline Age, years (mean \pm SD) & $67.8 \pm 10.4$ & $64.4 \pm 10.4$ & 0.376 \\
\hline Gender (male/female) & $15 / 5$ & $15 / 6$ & 0.796 \\
\hline $\mathrm{BMI}, \mathrm{kg} / \mathrm{m}^{2}($ mean $\pm \mathrm{SD})$ & $23.0 \pm 3.6$ & $23.6 \pm 3.8$ & 0.630 \\
\hline Preoperative anemia & 0 & 1 & \\
\hline Preoperative high CEA & 10 & 8 & 0.443 \\
\hline $\begin{array}{l}\text { Tumor location (distance } \\
\text { from anus, } \mathrm{cm}, \text { mean } \pm \mathrm{SD} \text { ) }\end{array}$ & $12.3 \pm 2.5$ & $8.9 \pm 3.3$ & 0.116 \\
\hline $\begin{array}{l}\text { Tumor maximum diameter } \\
(\mathrm{cm}, \text { mean } \pm \mathrm{SD})\end{array}$ & $4.7 \pm 1.2$ & $4.0 \pm 1.5$ & 0.225 \\
\hline TNM stage & & & 0.698 \\
\hline 0 & 1 & & \\
\hline I & 8 & 9 & \\
\hline II & 6 & 8 & \\
\hline III & 5 & 4 & \\
\hline pT stage & & & 0.997 \\
\hline Tis & 1 & 1 & \\
\hline $\mathrm{T} 1$ & 2 & 2 & \\
\hline $\mathrm{T} 2$ & 6 & 7 & \\
\hline $\mathrm{T} 3$ & 11 & 11 & \\
\hline pN stage & & & 0.837 \\
\hline N0 & 13 & 13 & \\
\hline N1 & 7 & 8 & \\
\hline Dukes' stage & & & 0.904 \\
\hline A & 5 & 6 & \\
\hline B & 8 & 9 & \\
\hline $\mathrm{C}$ & 7 & 6 & \\
\hline $\begin{array}{l}\text { Postoperative adjuvant } \\
\text { chemotherapy }\end{array}$ & 6 & 14 & 0.019 \\
\hline
\end{tabular}

There was no significant difference between the LS and OS groups with the Dixon operation regarding general clinical data $(\mathrm{P}>0.05)$, apart from postoperative adjuvant chemotherapy $(\mathrm{P}<0.05)$. LS, laparoscopic surgery; OS, open surgery; BMI, body mass index; $\mathrm{SD}$, standard deviation; CEA, carcinoembryonic antigen; TNM, tumor-node-metastasis.

Statistical analysis. All obtained data were analyzed with the SPSS 19.0 statistical software (SPSS Inc., Chicago, IL, USA). Measurement data were expressed as mean \pm standard deviation. The Student's $t$-test was used for continuous variables and the Chi-square test for categorical variables. In addition, the Kaplan-Meir method was used for survival comparison. $\mathrm{P}<0.05$ indicated a statistically significant difference.

\section{Results}

Comparison between the LS and OS groups in patients undergoing the Dixon procedure. For patients undergoing the Dixon procedure, the LS group had a longer operation time compared with the OS group (271.2 \pm 56.2 vs. $216.0 \pm 62.7 \mathrm{~min}$,
Table III. Comparison of general clinical data between the LS and OS groups with the Miles operation.

\begin{tabular}{|c|c|c|c|}
\hline Parameters & $\begin{array}{l}\text { LS group } \\
\quad(\mathrm{n}=11)\end{array}$ & $\begin{array}{l}\text { OS group } \\
(\mathrm{n}=12)\end{array}$ & P-value \\
\hline Age, years $($ mean $\pm S D)$ & $62.2 \pm 11.6$ & $57.5 \pm 16.6$ & 0.555 \\
\hline Gender (male/female) & $3 / 8$ & $4 / 8$ & 0.752 \\
\hline $\mathrm{BMI}, \mathrm{kg} / \mathrm{m}^{2}($ mean $\pm \mathrm{SD})$ & $22.9 \pm 3.0$ & $23.0 \pm 2.8$ & 0.619 \\
\hline Preoperative anemia & 2 & 4 & \\
\hline Preoperative high CEA & 8 & 6 & 0.265 \\
\hline $\begin{array}{l}\text { Tumor location (distance } \\
\text { from anus, } \mathrm{cm} \text {; mean } \pm \mathrm{SD} \text { ) }\end{array}$ & $4.4 \pm 2.4$ & $4.0 \pm 1.0$ & 0.814 \\
\hline $\begin{array}{l}\text { Tumor maximum diameter, } \\
\mathrm{cm}(\text { mean } \pm \mathrm{SD})\end{array}$ & $4.5 \pm 1.7$ & $5.1 \pm 2.6$ & 0.557 \\
\hline TNM stage & & & 0.697 \\
\hline 0 & & 1 & \\
\hline I & 6 & 6 & \\
\hline II & 4 & 3 & \\
\hline III & 1 & 2 & \\
\hline pT stage & & & 0.709 \\
\hline Tis & 1 & 0 & \\
\hline $\mathrm{T} 1$ & 1 & 2 & \\
\hline $\mathrm{T} 2$ & 4 & 4 & \\
\hline $\mathrm{T} 3$ & 5 & 6 & \\
\hline $\mathrm{pN}$ stage & & & 0.924 \\
\hline No & 9 & 10 & \\
\hline N1 & 2 & 2 & \\
\hline Dukes' stage & & & 0.925 \\
\hline A & 5 & 5 & \\
\hline $\mathrm{B}$ & 4 & 4 & \\
\hline $\mathrm{C}$ & 2 & 3 & \\
\hline $\begin{array}{l}\text { Postoperative adjuvant } \\
\text { chemotherapy }\end{array}$ & 6 & 10 & 0.134 \\
\hline
\end{tabular}

There was no significant difference between the LS and OS groups with the Miles operation regarding general clinical data $(\mathrm{P}>0.05)$. LS, laparoscopic surgery; OS, open surgery; BMI, body mass index; $\mathrm{SD}$, standard deviation; CEA, carcinoembryonic antigen; TNM, tumor-node-metastasis.

respectively; $\mathrm{P}=0.036$ ), and a shorter time to oral intake (3. $0 \pm 0.9$ vs. $4.7 \pm 1.0$ days, respectively; $\mathrm{P}=0.000$ ). There was no significant difference between the LS and OS groups in terms of intraoperative blood loss $(107.1 \pm 69.4$ vs. $166.4 \pm 81.6 \mathrm{ml}$, respectively; $\mathrm{P}=0.096)$, number of lymph nodes retrieved ( $7 \pm 4$ vs. $6 \pm 6$, respectively; $\mathrm{P}=0.604)$, duration of postoperative hyperthermia (2.6 \pm 0.5 vs. $2.6 \pm 1.6$ days, respectively; $\mathrm{P}=0.930)$ and hospitalization time (19.8 \pm 3.8 vs. $25.8 \pm 5.2$ days, respectively; $\mathrm{P}=0.067$ ). In addition, there was no significant difference between the LS and OS groups with the Dixon operation regarding 3-year tumor-free survival rate (35.0 vs. $38.1 \%$, respectively; $\mathrm{P}=0.837$ ), as indicated in Table IV.

Comparison between the LS and OS groups in patients undergoing the Miles procedure. For patients undergoing 
Table IV. Comparison of therapeutic effect between the LS group and OS groups with the Dixon operation.

\begin{tabular}{lcr}
\hline Parameters & LS group (n=20) & OS group (n=21) \\
\hline Operation time, min (mean \pm SD) & $271.2 \pm 56.2$ & $216.0 \pm 62.7$ \\
Intraoperative blood loss, ml (mean \pm SD) & $107.1 \pm 69.4$ & $166.4 \pm 81.6$ \\
Number of lymph nodes retrieved (mean \pm SD) & $7 \pm 4$ & $6 \pm 6$ \\
Time to oral intake, days (mean \pm SD) & $3.0 \pm 0.9$ & $4.7 \pm 1.0$ \\
Duration of postoperative hyperthermia, days (mean \pm SD) & $2.6 \pm 0.5$ & $2.6 \pm 1.6$ \\
Postoperative complications & & 0.604 \\
Pulmonary infection & 0 & 0.930 \\
Intestinal adhesion & 0 & 1 \\
Fistula & 1 & 0 \\
Hospitalization, days (mean \pm SD) & $19.8 \pm 3.8$ & $25.8 \pm 5.2$ \\
3-year tumor-free survival rate (\%) & 35.0 & 38.1 \\
Postoperative recurrence/metastasis & & 0.067 \\
Local recurrence & 1 & 0.837 \\
Pulmonary metastasis & 0 & 1 \\
Multiple metastasis & 0 & 1
\end{tabular}

There was no significant difference between the LS and OS groups with the Dixon operation regarding therapeutic effect $(\mathrm{P}>0.05)$, apart from operation time and time to oral intake $(\mathrm{P}<0.05)$. LS, laparoscopic surgery; OS, open surgery; SD, standard deviation.

Table V. Comparison of therapeutic effect between the LS and OS groups with the Miles operation.

\begin{tabular}{lcc}
\hline Parameters & LS group (n=11) & OS group (n=12) \\
\hline Operative time, min (mean \pm SD) & $310.5 \pm 93.2$ & $284.2 \pm 77.2$ \\
Intraoperative blood loss, ml (mean \pm SD) & $211.1 \pm 74.0$ & $280.0 \pm 164.3$ \\
Number of lymph nodes retrieved (mean \pm SD) & $5 \pm 7$ & $8 \pm 4$ \\
Time to oral intake, days (mean \pm SD) & $3.1 \pm 0.4$ & $3.7 \pm 1.0$ \\
Duration of postoperative hyperthermia, days (mean \pm SD) & $2.4 \pm 1.2$ & $3.2 \pm 1.0$ \\
Postoperative complications & & 0.429 \\
Pulmonary infection & 1 & 0.210 \\
Intestinal adhesion & 0 & 1 \\
Fistula & 0 & 0 \\
Hospitalization time, days (mean \pm SD) & $26.6 \pm 7.8$ & $31.5 \pm 10.0$ \\
3-year tumor-free survival rate, $\%$ & 36.4 & 33.3 \\
Postoperative recurrence/metastasis & & 0.314 \\
Local recurrence & 0 & 0.879 \\
Pulmonary metastasis & 2 & 0 \\
Multiple metastasis & 1 & 1 \\
\hline
\end{tabular}

There was no significant difference between the LS and OS groups with the Miles operation regarding therapeutic effect (P>0.05). LS, laparoscopic surgery; OS, open surgery; SD, standard deviation.

the Miles procedure, there was no significant difference between the LS and OS groups in terms of operation time (310.5 \pm 93.2 vs. $284.2 \pm 77.2 \mathrm{~min}$, respectively; $\mathrm{P}=0.551$ ), intraoperative blood loss $(211.1 \pm 74.0$ vs. $280.0 \pm 164.3 \mathrm{ml}$, respectively; $\mathrm{P}=0.416)$, number of lymph nodes retrieved $(5 \pm 7$ vs. $8 \pm 4$, respectively; $\mathrm{P}=0.429)$, time to oral intake (3.1 \pm 0.4 vs. $3.7 \pm 1.0$, respectively; $\mathrm{P}=0.203)$, duration of postoperative hyperthermia ( $2.4 \pm 1.2$ vs. $3.2 \pm 1.0$ days, respectively;
$\mathrm{P}=0.210)$ and hospitalization time ( $26.6 \pm 7.8$ vs. $31.5 \pm 10.0$ days, respectively; $\mathrm{P}=0.314)$. Furthermore, there was no significant difference between the LS and OS groups regarding 3 -year tumor-free survival rate (36.4 vs. 33.3\%, respectively; $\mathrm{P}=0.879$ ), as indicated in Table $\mathrm{V}$.

The operation was successfully performed in all the patients, without damage to the adjacent organs and supplying blood vessels. Only 1 case of laparoscopic Dixon operation 


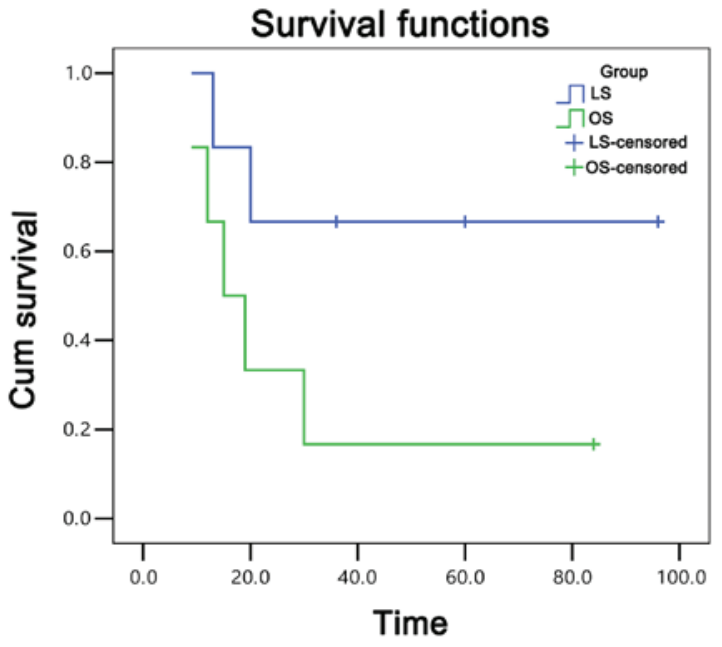

Figure 1. Survival curves of the LS and OS groups with the Dixon operation. LS, laparoscopic surgery; OS, open surgery.

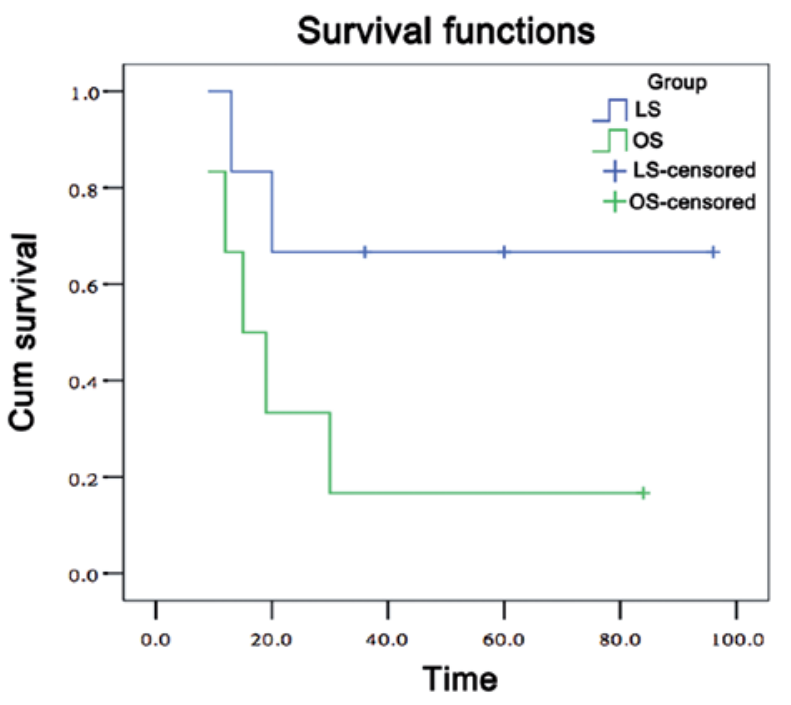

Figure 2. Survival curves of the LS and OS groups with the Miles operation. LS, laparoscopic surgery; OS, open surgery.

was converted to the open Dixon procedure due to bleeding. There was no circumferential margin positivity in any of the patients. All cases of preoperative anemia were corrected prior to surgery. There was 1 patient with a distal surgical margin at a distance of only $1 \mathrm{~cm}$ from the lesion (pathological TNM stage III, pathological Dukes' stage C), who was treated postoperatively with the FOLFOX chemotherapeutic regimen; the patient survived for 4 years. Apart from patients undergoing the Miles operation, no patient received a diverting loop ostomy. Intestinal decompression measures were commonly applied; a plastic thread tube with negative pressure was used intraoperatively to suction the intestinal contents when necessary. Every effort was made to secure the bowel anastomosis during the first phase of the operation. Therefore, unless there was severe inflammation or edema in the bowel wall caused by obstruction, a diverting loop stoma was seldom adopted. In addition, there was 1 case of postoperative pulmonary infection among LS group patients undergoing the Miles operation, 2 cases of postoperative pulmonary infection in the OS group
(1 Dixon and 1 Miles operation) and 2 cases of postoperative intestinal adhesion in the OS group (1 Dixon and 1 Miles operation). Only 1 patient undergoing the laparoscopic Miles operation developed the postoperative complication of chronic perineal fistula; the patient recovered following fistulectomy. No other patients developed fistula. There was 1 case of local recurrence (descending colon cancer) 1.5 years later in the LS group with the Dixon operation, and 1 case of local recurrence (cancer of the hepatic flexure) 1 year later in the OS group with the Dixon operation. There were 2 cases of lung metastasis in the LS group with the Miles operation (1 at 6 years and 1 at 5 years after the operation), and 2 cases of lung metastasis in the OS group (1 within the first year after the Dixon operation, and 1 in the second year after the Miles operation). Furthermore, there was 1 case of multiple metastases (lung, liver and urethra) in the LS group $>3$ years after the Miles operation, and 1 case of multiple metastases (bladder and lung) in the OS group $>1$ year after the Dixon operation.

In the 3 years after the operation, 1 case was lost to follow-up from the LS group and 2 cases from the OS group. The 95\% confidence interval of the LS and OS groups with the Dixon operation were 78-116 and 109-184 months, respectively. There was no significant difference between the two groups regarding postoperative chemotherapy $(\mathrm{P}>0.05)$. The survival curves of the OS and LS groups with the Dixon operation are shown in Fig. 1. Similarly, the 95\% confidence interval of the LS and OS group with Miles operation were 39-100 and 7.4-48 months, respectively. There was no significant difference in postoperative chemotherapy between these two groups $(\mathrm{P}>0.05)$. The survival curves of the OS and LS groups with the Miles operation are shown in Fig. 2.

\section{Discussion}

Rectal cancer is the third most common type of cancer worldwide, with a yearly increasing incidence. Surgical resection is the preferred curative approach to cancer treatment. Laparoscopic surgery is a rapidly advancing, minimally invasive operative procedure. Laparoscopic colon surgery was first reported in 1991 (5), after which time it has been increasingly performed worldwide for the treatment of colorectal cancer. In 1993, laparoscopic colectomy was introduced in China, and it has become a proficient and widely used method over the past 10 years. Laparoscopic colectomy has been generally acknowledged as an effective therapy (6). However, laparoscopic surgery for rectal cancer had not been recommended outside a clinical trial (7), and remains controversial due to the limited availability of long-term data on survival and recurrence (8). As a therapy for malignant tumors, the operative safety and long-term effects of laparoscopic surgery are under constant scrutiny.

In this study, the operation time with the laparoscopic Dixon operation was longer compared with that with open surgery. The difference was statistically significant, as laparoscopic surgery was more complicated and the operators did not have adequate technical proficiency. Laparoscopic radical resection of rectal carcinoma is an operation with distinct anatomical characteristics and it is crucial to determine the accurate anatomical plane and distinguish anatomic landmarks during laparoscopy. Operative laparoscopy mainly consists of three steps, namely vessel separation, lymph node dissection and 
ensuring a tumor-free resection margin. In this study, there was no significant difference between laparoscopic and open surgery with the Miles operation for rectal cancer treatment. Although technically challenging, laparoscopic rectal cancer surgery may provide a more magnified view of the pelvic cavity compared with open surgery, which may facilitate the resection of the mesorectum with a higher accuracy and greater ease (9). The duration of postoperative hyperthermia reflects the degree of trauma. In this study, there was no significant difference in the duration of postoperative hyperthermia between laparoscopic and open surgery, although the operation time of laparoscopic surgery was longer compared with that of open surgery, possibly due to the minimal invasiveness of the laparoscopic procedure. Furthermore, compared with open surgery, the laparoscopic method is associated with smaller incisions, less tissue damage, less postoperative discomfort, shorter time to ambulation and a lower incidence of postoperative complications. The visual field under a laparoscope is broader, which is helpful for intraoperative exploration, particularly in patients with tumors of the lower rectum. In addition, the laparoscope may be inserted into the pelvis minor and provide a better view of the surgical field, which may be helpful in distinguishing and preserving key structures, such as the pelvic nerve plexus, so as to avoid postoperative urinary retention and sexual dysfunction. Moreover, the cavitation effect produced by the ultrasonic knife on the tissue plane may enable faster and more accurate dissection of the rectum, so that the pelvic nerve plexus is protected and the risk of damage to the sacral venous plexus is reduced. With accumulation of technical experience and an increasing number of skilled operators, the operation time for laparoscopic rectal cancer resection may be further shortened.

Dural et al (8) reported that patients undergoing laparoscopic surgery for rectal cancer had similar incidence rates of complications, circumferential resection margin involvement, and long-term outcomes compared with those undergoing open surgery. However, laparoscopic surgery for rectal cancer had the advantage of minimal invasiveness. These conclusions were in agreement with ours. Although laparoscopic surgery may require more advanced technical skills, the same long-term oncological results were obtained with this technique compared with open surgery (8). In this study, the postoperative complications with laparoscopic surgery, such as pulmonary infection and intestinal adhesions, were similar to those of open surgery. The time to oral intake of the LS group was shorter compared with that of the OS group, which meant faster gastrointestinal recovery following laparoscopic surgery. Patients in the LS group had a shorter hospital stay, which reduced the cost of medical treatment and the burden of the patients. In the literature, laparoscopy was found to be cost-effective for rectal cancer surgery, improving health care expenditure as well as patients' outcomes. For selected patients, laparoscopic rectal cancer resection may shorten the hospitalization time, operating time and resource utilization (10). In addition, oncologic clearance of the resection margins and the number of lymph nodes removed were similar between the laparoscopic and open surgery groups $(9,11-14)$. This was consistent with our results. Distal margins remain the most widely debated pathological parameter for total mesorectal excision surgery. Initially, a $5-\mathrm{cm}$ distal margin was considered to be necessary. However, this criterion was refuted in the 1980s when the distal tumor spread was found to be $<5 \mathrm{~cm}$ (15). Recently, several studies suggested that $<1 \mathrm{~cm}$ or even a merely negative margin may be acceptable $(16,17)$. The extent of tumor removal and metastatic lymph node dissection are key to rectal cancer surgery and are associated with the quality of life, recurrence rate and survival rate postoperatively.

Two recent meta-analyses demonstrated that a clear benefit was conferred by the construction of a stoma, with significantly low leakage and reoperation rates $(18,19)$. Although a stoma was not constructed in our patients, there was only 1 case of chronic perineal fistula in a male patient with a stage III tumor undergoing the laparoscopic Miles operation. The patient recovered following fistulectomy. The inherent drawbacks of laparoscopic rectal resection, such as the narrow space in which to insert the stapling device, inadequate traction and the oblique cutting angle, may require multiple applications of the linear stapler. A recent study reported that an unduly long transection line with multiple staples may result in anastomotic leakage $(20,21)$. In this study, one-stage anastomosis of the colon and rectum was feasible in the majority of the patients, which requires full preoperative upper intestinal preparation (emptying), sufficient broad anastomosis with good blood supply and without tension, and distal intestinal patency. During the Dixon operation, prior to inserting the stapling apparatus, the anus was stretched to 4-6 fingers. A drainage tube was inserted into the pelvic cavity. All those measures were effective in preventing anastomotic fistula formation. Furthermore, Park et al reported that male gender, low anastomosis, preoperative chemoradiation, advanced tumor stage, perioperative bleeding and multiple firings of the linear stapler increased the risk of anastomotic leakage following laparoscopic surgery for rectal cancer. A diverting stoma may be mandatory in patients with $\geq 2$ of the abovementioned risk factors (22).

In recent years, accumulating evidence from single- and multicenter randomized trials indicated that laparoscopic surgery for rectal cancer was associated with earlier postoperative recovery, lower morbidity and better short-term quality of life compared with open surgery (23). Thus, it was concluded that laparoscopic surgery was associated with a greater short-term benefit compared with open surgery. However, this approach was not widely accepted, partly due to its technical difficulties and certain doubts regarding its long-term oncological outcomes. Recent randomized controlled trials have demonstrated that laparoscopic surgery for colon cancer is similar to open surgery in terms of oncological outcome, and several advantages of laparoscopic surgery have been reported regarding short-term outcomes. However, controversy persists regarding the appropriateness of laparoscopic surgery for patients with rectal carcinoma due to concerns regarding the safety of the procedure and the uncertainty of the long-term outcome (24). The first randomized study describing long-term oncological outcomes was reported by Braga et al (14), who observed that there was no difference between the two approaches in terms of 5-year overall and disease-free survivals. Laurent et al (25) reported that laparoscopic surgery was an independent predictor of better overall survival, but not cancer-specific survival, for rectal cancer. The authors concluded that the type of surgery did not affect cancer outcome. Yamamoto et al reported that 
laparoscopic surgery may be used for safe and radical resection of clinical stage 0/I rectal cancer, without increasing the short-term surgical and oncological risks (26). The study of Lacy et al (27) demonstrated that, compared with open surgery, laparoscopic surgery may confer a survival benefit in patients with rectal cancer of Duke's stage $C$. These may be attributed to the reduced contact of the tumor with the abdominal organs during extraction, minimizing the risk of spread, vision amplification with the laparoscopic camera, vascular ligation of higher precision, and more thorough regional lymph node dissection. In our study, the postoperative survival rate of laparoscopic surgery was similar with that of open surgery, indicating that laparoscopic surgery for rectal cancer is safe and feasible.

In this study, although there was a difference in postoperative chemotherapy between patients in the LS and the OS groups undergoing the Dixon operation, there was no significant difference in long-term outcome between the two surgeries. The effect of chemotherapy on long-term survival will be addressed in another study. In this study, there were significant differences between laparoscopic and open surgery for rectal cancer in terms of short-term results, such as operation time and hospitalization. However, there was no significant difference regarding long-time survival rate. In addition, the minimal invasiveness and safety of laparoscopic surgery are acknowledged by an increasing number of doctors and patients. It is considered that, with the continuous advances in technology, accumulation of clinical experience and improving team collaboration, laparoscopic surgery will be more widely applied by more medical centers specializing on rectal cancer treatment. We consider laparoscopic surgery to be a safe and feasible option for rectal cancer treatment.

\section{Acknowledgements}

We would like to thank our colleagues H.J.S., L.S.J. and Z.J. for their assistance and collaboration.

\section{References}

1. Lai SQ, Ju FH and Wang GQ: The clinical epidemiological characteristics of 704 cases of colorectal cancer from 2004-2008. China Cancer 19: 111-113, 2010.

2. Zhou XY,Zhang JL and Wang ZK: Comparative study of laparoscopic and open surgery for colorectal cancer: Short-term results. J Laparosc Surg 17: 199-203.

3. Wang SY and Chen ZY: Short-term outcomes of laparoscopy surgery for colorectal cancer: A comparative study. Fudan Univ J Med Sci 37: 92-99, 2010.

4. Pugliese R, DiLernia S, Sansonna F, Ferrari GC, Maggioni D, Scandroglio I, Costanzi A, Magistro C and De Carli S: Outcomes of laparoscopic Miles' operation in very-low rectal adenocarcinoma. Analysis of 32 cases. Eur J Surg Oncol 33: 49-54, 2007.

5. Jacobs M, Verdeja JC and Goldstein HS: Minimally invasive colon resection (laparoscopic colectomy). Surg Laparosc Endosc 1: 144-150, 1991.

6. Lezoche E, Feliciotti F, Paganini AM, Guerrieri M, De Sanctis A and Campagnacci R: Laparoscopic colonic resection. J Laparoendose Adv Surg Tech A 11: 401-408, 2004.

7. Bipat S, Glas AS, Slors FJ, Zwinderman AH, Bossuyt PM and Stoker J: Rectal cancer: Local staging and assessment of lymph node involvement with endoluminal US, CT, and MR imaging-a meta-analysis. Radiology 232: 773-783, 2004.

8. Dural AC, Keskin M, Balik E, Akici M, Kunduz E, Yamaner S, Asoglu Q, Gulluoglu M and Bugra D: The role of the laparoscopy on circumferential resection margin positivity in patients with rectal cancer: Long-term outcomes at a single high-volume institution. Surg Laparosc Endosc Percutan Tech 25: 129-137, 2015.
9. Lujan J, Valero G, Hernandez Q, Sanchez A, Frutos MD and Parrilla P: Randomized clinical trial comparing laparoscopic and open surgery in patients with rectal cancer. Br J Surg 96: 982-989, 2009

10. Keller DS, Champagne BJ, Reynolds HL Jr, Stein SL and Delaney CP: Cost-effectiveness of laparoscopy in rectal cancer. Dis Colon Rectum 57: 564-569, 2014.

11. Guillou PJ, Quirke P, Thorpe H, Walker J, Jayne DG, Smith AM, Heath RM and Brown JM; MRC CLASICC trial group: Short-term endpoints of conventional versus laparoscopic-assisted surgery in patients with colorectal cancer (MRC CLASICC trial): Multicentre, randomised controlled trial. Lancet 365: 1718-1726, 2005.

12. Kang SB, Park JW, Jeong SY, Nam BH, Choi HS, Kim DW, Lim SB, Lee TG, Kim DY, Kim JS, et al: Open versus laparoscopic surgery for mid or low rectal cancer after neoadjuvant chemoradiotherapy (COREAN trial): Short-term outcomes of an open-label randomised controlled trial. Lancet Oncol 11: 637-645, 2010.

13. Zhou ZG, Hu M, Li Y, Lei WZ, Yu YY, Cheng Z, Li L, Shu Y and Wang TC: Laparoscopic versus open total mesorectal excision with anal sphincter preservation for low rectal cancer. Surg Endosc 18: 1211-1215, 2004.

14. Braga M, Frasson M, Vignali A, Zuliani W, Capretti G and Di Carlo V: Laparoscopic resection in rectal cancer patients: Outcome and cost-benefit analysis. Dis Colon Rectum 50: 464-471, 2007.

15. Pollett WG and Nicholls RJ: The relationship between the extent of distal clearance and survival and local recurrence rates after curative anterior resection for carcinoma of the rectum. Ann Surg 198: 159-163, 1983.

16. Bernstein TE, Endreseth BH, Romundstad P and Wibe A; Norwegian Colorectal Cancer Registry: What is a safe distal resection margin in rectal cancer patients treated by low anterior resection without preoperative radiotherapy? Colorectal Dis 14: e48-e 55, 2012.

17. Fitzgerald TL, Brinkley J and Zervos EE: Pushing the envelope beyond a centimeter in rectal cancer: Oncologic implications of close, but negative margins. J Am Coll Surg 213: 589-595, 2011.

18. Tan WS, Tang CL, Shi L and Eu KW: Meta-analysis of defunctioning stomas in low anterior resection for rectal cancer. Br J Surg 96: 462-472, 2009.

19. Huser N, Michalski CW, Erkan M, Schuster T, Rosenberg R, Kleeff $\mathbf{J}$ and Friess H: Systematic review and meta-analysis of the role of defunctioning stoma in low rectal cancer surgery. Ann Surg 248: 52-60, 2008.

20. Kim JS, Cho SY, Min BS and Kim NK: Risk factors for anastomotic leakage after laparoscopic intracorporeal colorectal anastomosis with a double stapling technique. J Am Coll Surg 209: 694-701, 2009.

21. Ito M, Sugito M, Kobayashi A, Nishizawa Y, Tsunoda Y and Saito N: Relationship between multiple numbers of stapler firings during rectal division and anastomotic leakage after laparoscopic rectal resection. Int J Colorectal Dis 23: 703-707, 2008.

22. Park JS, Choi GS, Kim SH, Kim HR, Kim NK, Lee KY, Kang SB, Kim JY, Lee KY, Kim BC, et al: Multicenter analysis of risk factors for anastomotic leakage after laparoscopic rectal cancer excision: The Korean laparoscopic colorectal surgery study group. Ann Surg 257: 665-671, 2013.

23. Ng SS, Lee JF, Yiu RY, Li JC, Hon SS, Mak TW, Leung WW and Leung KL: Long-term oncologic outcomes of laparoscopic versus open surgery for rectal cancer: A pooled analysis of 3 randomized controlled trials. Ann Surg 259: 139-147, 2014.

24. Jayne DG, Guillou PJ, Thorpe H, Quirke P, Copeland J, Smith AM, Heath RM and Brown JM; UK MRC CLASICC Trial Group: Randomized trial of laparoscopic-assisted resection of colorectal carcinoma: 3-year results of the UK MRC CLASICC Trial Group. J Clin Oncol 25: 3061-3068, 2007.

25. Laurent C, Leblanc F, Wütrich P, Scheffler M and Rullier E: Laparoscopic versus open surgery for rectal cancer: Long-term oncologic results. Ann Surg 250: 54-61, 2009.

26. Yamamoto S, Ito M, Okuda J, Fujii S, Yamaguchi S, Yoshimura K, Sugihara K and Watanabe M; Japan Society of Laparoscopic Colorectal Surgery: Laparoscopic surgery for stage 0/I rectal carcinoma: Short-term outcomes of a single-arm phase II trial. Ann Surg 258: 283-288, 2013.

27. Lacy AM, García-Valdecasas JC, Delgado S, Castells A, Taurá P, Piqué JM and Visa J: Laparoscopy-assisted colectomy versus open colectomy for treatment of non-metastatic colon cancer: A randomised trial. Lancet 359: 2224-2229, 2002. 